\title{
BIMReL: The Interoperable BIM Library for Construction Products Data Sharing
}

\author{
Sonia Lupica Spagnolo, Gustavo Amosso, Alberto Pavan and Bruno Daniotti
}

\begin{abstract}
BIMReL is an online platform for construction industry operators (primarily manufacturers, but also designers, construction companies, facility managers, trade associations and owners) because it allows using and sharing all the technical and commercial data of construction products. Moreover, it helps collecting and exchanging data about performances, durability and environmental indicators in a simple and user-friendly way. The creation of such a tool became necessary because, despite many interesting developments in Information and Communication Technologies (ICT), the data exchange along the building process is hardly efficient and still mainly based on a transmission of paper documents, on a plurality of classification systems, as well as on a use of different criteria and practices. The lack of a common structure for data storage involves different inefficiencies and it also may affect such essential aspects for users as comfort, safety, health, energy saving and environmental sustainability. Inefficiency means a waste of time (and therefore a waste of money) because it often may cause complicated variations during the construction stage or misunderstandings, which may lead to legal disputes. Therefore, BIMReL has been developed in order to provide a new digital tool for sharing product data in a BIM environment and such as to enable the user to choose the most proper product but also to easily retrieve all useful information during its use, its maintenance or its disposal.
\end{abstract}

Keywords BIM library $\cdot$ Product data template $\cdot$ CE marking $\cdot$ Interoperability

\section{The Development of an Interoperable Platform}

Digital solutions are often adopted for managing information in an ordered structure. Several efforts have been devoted for developing solutions and optimising methods for sharing information about buildings. Referring to the level of products, two

\footnotetext{
S. Lupica Spagnolo (凶) · G. Amosso · A. Pavan · B. Daniotti Architecture Built Environment and Construction Engineering-ABC Department, Politecnico di Milano, Milan, Italy

e-mail: sonia.lupica@polimi.it

B. Daniotti et al. (eds.), Digital Transformation of the Design, Construction and Management Processes of the Built Environment, Research for Development, https://doi.org/10.1007/978-3-030-33570-0_4
} 
improvements in the management of information are represented by the development of BIM libraries (Duddy et al. 2013; Kim et al. 2015; Pasini et al. 2017) and the definition of Product Data Templates (PDTs) (Gudnason and Pauwels 2016). BIM libraries are tools published on the web for hosting objects describing products; PDTs are structures for defining standardised data content, listing attributes required for describing objects from a geometrical and alpha-numerical point of view (Lucky 2019). The BIMReL platform is freely accessible by a website and it has been implemented to maximise and simplify its use by different stakeholders in the construction industry who can upload and exchange all the technical and commercial product data in a user-friendly way (Lupica Spagnolo et al. 2017). With the proposed system, it is in fact possible to check easily all the parameters that are necessary to guarantee the seven basic requirements of constructions works (i.e. mechanical resistance and stability, safety in case of fire, hygiene, health and the environment, safety and accessibility in use, protection against noise, energy economy and heat retention and sustainable use of natural resources) in a completely new, effective and efficient way.

As a result, end users such as property owners and clients (individuals or public administrations), as well as designers and facility managers, for whom it is now extremely difficult to find a lot of data to help in choosing products, will have access to information in an easy, transparent and cost-free way, to be able to choose and define the technical solutions that best fit their needs and requirements. Exploiting BIM and from a perspective of its active and effective promotion, also in view of the application of the Italian Procurement Code (Legislative Decree No. 50/2016), the platform associates this information to the BIM objects, thereby allowing their efficient management.

The information system created is profoundly different from the current libraries of BIM objects that can usually be found online, because it creates the first life cycle management of all BIM-ready information, namely to ensure the exploitation of the efficiency of calculation, simulation and modelling automation. This system uses techniques and tools capable of simplifying the interaction between physical objects (the building elements) and the digital world in which these objects are represented. QR-codes, integrations with smartphones and tablets and advanced research systems can support all the actions of the supply chain operators in their daily operations. The user can easily and intuitively compare materials and technologies on the basis of different validated and available information in a transparent and, therefore, manageable way, along the life cycle (from production to disposal/recovery) of the constructed facility where they are placed. An interoperable library is not based on proprietary formats for exchanging information, but it has to undertake the development of solutions for connecting information through interoperable web-services so to collect data in a neutral format (Pasini et al. 2017). In such a way, the solution is not software-dependent, therefore, also the efforts and the difficulty in maintaining consistency between the representations for the different software over time are reduced (Duddy et al. 2013).

BIMReL, therefore, ranks as an innovative and integrated supply chain tool of business processes and models from an export perspective, thanks to the systematisation aimed at the digitalisation of the entire construction sector in the wake of 
Industry 4.0, as well as a smart tool for simplified and transparent management for all of the choices regarding products, materials and systems made by the different actors involved in the building process.

\section{Research Project Objectives}

The main objective of the project is the reduction of environmental impacts at every stage of the product life cycle ("from cradle to grave") as BIMReL first of all allows choosing construction products by comparing them not only on the basis of their technical-descriptive features, but also in the light of its environmental impact along the entire life cycle (Signorini et al. 2019): a special section is dedicated to the collection of environmental sustainability indicators in accordance with the UNI EN 15804:2014 (UNI, 2014) and ISO 21930:2017 (ISO, 2017), finally allowing the user to be able to make an informed choice in terms of sustainability. Nationally and internationally, there are databases with data for life cycle assessment data (LCA), but they are very poor of data, not well known, non-interoperable and difficult to use for non-experts, so BIMReL stands as the first and only full, interoperable and user-friendly international platform for sustainability for individual citizens, and of course for all other actors of the construction sector who require such information.

From the perspective of the smart supply chain, an integrated process chain is pursued by means of the total rationalisation of information flows from manufacturers to designers, to construction companies down to individual end users. That is so to streamline all phases of the construction process, as well as to ensure to the end-users, public or private clients full transparency concerning the safety, wellbeing, health and eco-sustainability requirements of products, entire technological packages or installation elements. A tracking of the changes made over time by the data owner, first of all, the manufacturer who will need to update technical specifications, trade or installation instructions, will ensure data reliability for the user. The platform also has the primary objective of promoting the manufacturing companies at national and international level, using an innovative and comprehensive communication channel and latest generation marketing tools that are already consolidated on other international web portals by the partner TraceParts.

A further pivotal purpose of the project is to push strongly toward virtual design systems so detailed as to provide the user with a realistic view. With BIMReL the approach to Building Information Modelling is amplified not only in the design phase but also in the delivery and operational phase of constructed works over time. 


\section{Compliance with the Reference Framework}

In BIMReL, the aim is to exploit ICT's potential to digitise the construction sector with the main intention of making it effectively sustainable, in the broadest sense of the term, economically, environmentally and socially.

Aware of this need, different players in the construction industry have recently developed a consensual standard, UNI/TS 11337-3-2015 (UNI, 2015), which provides key guidelines for developing a product data template. However, the tools that are in accordance with these rules are missing. The BIMReL project is an innovative tool that is compliant with the UNI standards, as well as already in line with the latest international standards on interoperability (developed by ISO TC 59 SC13 and CEN TC 442), durability (developed from the ISO standard 15686) and sustainability (developed by the ISO TC 59 SC17 and CEN TC 350 standards).

The platform, built on a regulatory basis and using the format of the product technical datasheet indicated in UNI/TS 11300-3:2015, allows the unambiguous identification of the products (Category, Type and Standard) and the essential and voluntary characteristics obtained from the reference product standards, enriched by all the information deemed necessary by the market. On one hand it allows manufacturers to use an advanced matrix of data collection, and on the other hand it allows users to be able to effectively compare the features of different products. If you then consider that data are structured like database fields, it is also clear that the efficiency of applying all the research filters, as well as automatic retrieving or calculating using software tools offers significant benefits in terms of result reliability and processing speed.

In Fig. 1, the logical process of unambiguous object classification is shown: it follows a precise workflow that starts from the individualization of the family, moving then to the selection of its macro-category (if any), its category, its typology and the reference standard (if any).

In this way, it is, therefore, possible to ensure maximum speed of circulation for new digital work methodologies, first of all, the one provided by the introduction of BIM, but also and especially to guarantee the possibility of checking by end-users.

\section{The Development of an Advanced BIM Library for the Construction Sector}

The platform comes as a library of BIM objects, but with an innovative component. In fact, BIMReL three-dimensional digital objects not only possess the graphic geometries, but they also contain every descriptive attribute of the product so as to be useful to the user himself. Moreover, specific tools allow a fast comparison of requirements and performances of products. These objects are then associated to a standardised data sheet already compliant with UNI/TS 11337-3:2015 and using a unique code. 
Fig. 1 Logical process of unambiguous object classification

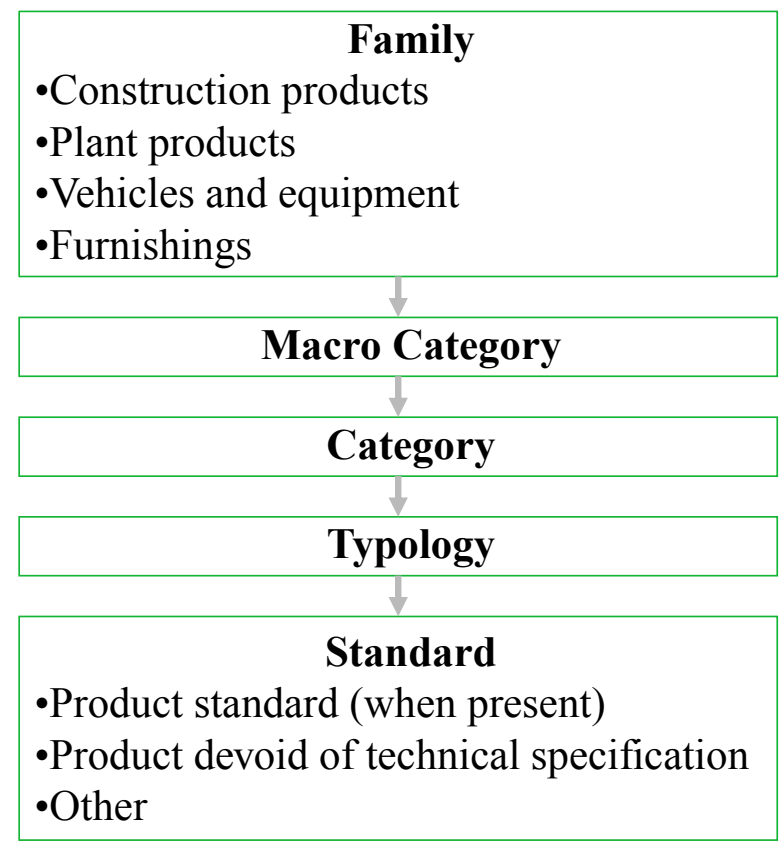

Thanks to the developed implementation of the BIM, a part of the platform enables direct dialogue between users/designers and manufacturers in order to customise certain products in the catalogue. This is in order to create increasingly defined 3D prints of products, whether they are building or plant structures, as well as scale models of entire buildings or parts thereof, in order to give the user an accurate and detailed preview of the construction asset. Conversely, from the BIM breakdown model it is also possible to prepare all the information for additive manufacturing, thus allowing new and pioneering manufacturing companies to fit smoothly into the building market, and at the same time for the users themselves to finally exploit the potential offered by this production approach.

\section{The Role of the Citizen in the Pursuit of Sustainability}

With the BIMReL tool, even citizens can exert a new active role in a building process, thanks to an innovative system of information management that allows them to make aware choices that are not limited to the mere expression of aesthetic tastes or the pursuit of energy savings, but also contemplate the environmental implications.

Currently, in fact, the user who wants to make some environmentally friendly choices cannot help but rely on generic advertising claims such as 'environmentally friendly', 'sustainable', 'zero emission' or fathom out the real meaning of the various sustainability labels (the so-called eco-labels) that are gradually emerging. 
This information, however, is often misleading because it is generally related to just one phase of the advertised product's life cycle. What we need is to allow a global vision of the actual environmental impacts, translating the generic adjectives above mentioned into numerical magnitudes, which can, therefore, be mutually compared. This is possible if we can associate the objects to the values of the individual indicators of environmental sustainability, which have already been identified with their corresponding measurement unit inside the UNI EN 15804:2014 standard. Thus, as it has happened with energy certification, the most discerning users will be able to make choices on the basis of an 'environmental qualification' while still being able to effectively educate less careful users.

\section{The Project's Partners}

The leading partner of the Consortium is the Politecnico di Milano, which worked on the research proposal definition, on the project management and on the scientific development of BIMReL. To do this, various research groups were involved, mainly traceable to the $\mathrm{ABC}$ (Architecture, Built environment and Construction engineering) and DEIB (Electronic, Information and Bioengineering) departments.

One Team S.r.l. is an Italian company dedicated to consulting services and turnkey supplies in the design field (CAD, GIS, EDM/PDM/PLM, FM). It has been the main Italian Autodesk partner for more than 30 years, holding for it the Autodesk Platinum Partner and Autodesk Developer Network qualifications.

Inside the BIMReL project, One team has worked in particular on the experimental development, supporting the Politecnico in analysis and research tasks; it has implemented the software toolkit and also developed the technological interfaces interchange with the BIM\&Co portal.

Eventually, TraceParts is a leading global provider of 3D digital content for engineering. The company provides Internet-based solutions for creating and managing libraries of components, catalogues and product configurators. It also provides digital marketing services to help manufacturers promoting their products and services better.

\section{The Web Portal}

\subsection{User Management}

To have full access to the features of the web portal, registration is required. The new user could be a 'User' or a 'Manufacturer'. The latter figure is different from the former in that it will also insert a first corporate profile and will be enabled to upload content. 
Special features include the possibility of inserting the manufacturing plants, essential to the assessment of the environmental impacts according to the distance to be covered, and the company certifications of the registered office or of any production facility.

\subsection{New Product}

The insertion of a new product immediately shows the user ten points (see Table 1). The goal of BIMReL is to sensitise the user to compile all the points in their entirety. With reference to the amount of information provided in the BIM portals on the market, often limited to a small amount of data, it was considered appropriate not to make compiling all the points binding, with the exception of the clear definition of the product in point 1 and entry of the 'Commercial name'.

Currently, BIMReL contains more than 1 thousand of different classes of product, as graphically highlighted in Fig. 2.

\subsection{Edit and Review}

The 'Edit' button, as previously mentioned, allows to complete or change the inserted information.

While a company may continue to place products with the same properties, the declaration of performance number and lot number can change over time. Following the previous consideration, the possibility of generating a DoP history was introduced through the 'Review' action.

\subsection{XML (eXtensible Markup Language) and Digital CE}

All the information submitted is also made available in XML format, as this format is readable on any type of computer and will ensure a high level of interoperability.

In addition, what the BIMReL calls the 'Digital CE', i.e. the ability to extract the version in XML format with all of the DoP data, has been implemented.

\subsection{BIMReL IFC}

In the product section, besides having the original IFC file available, the user will have the option to download the "BIMREL IFC' containing information from the portal filtered according to the chosen LOD. An example is shown in Fig. 3. 
Table 1 Description sections of the product entry wizard

\begin{tabular}{|c|c|}
\hline Step & Description \\
\hline 1 & $\begin{array}{l}\text { It is a section that identifies the product within the BIMReL classification, based on the } \\
\text { identification of the same class (so if it is a construction or installation product, a } \\
\text { furniture, a vehicle or an equipment), then the macro-category (present, for example, for } \\
\text { the furniture, to be able to be grouped, for example, into office furniture), the category } \\
\text { (such as, for example, plaster mortar, thermal insulation, etc.), the product type and the } \\
\text { reference standard (if present). } \\
\text { The possible combinations already implemented (Family, Macro-category, Category, } \\
\text { Type and Standard) enable the user to uniquely classify each product and, depending on } \\
\text { that, allow the database to propose specific data in the following points }\end{array}$ \\
\hline 2 & $\begin{array}{l}\text { In this step, there is the opportunity to define the product commercially, to attribute } \\
\text { keywords, synonyms and encodings according to: Uniformat, OmniClass (Table 23), } \\
\text { MasterFormat, Uniclass and ETIM, to select the corresponding production plant and } \\
\text { insert the images that best represent the element }\end{array}$ \\
\hline 3 & $\begin{array}{l}\text { CE Marking and DoP (Declaration of performance). If you are inserting a construction } \\
\text { product subject to a harmonised standard, at this point, the fields of Regulation (EU) No } \\
305 / 2011 \text { (the European Parliament and the Council, 2011) will be shown, along with } \\
\text { the words 'optional field' for those sections that are not mandatory based on delegated } \\
\text { Regulation (EU) No. 574/2014 (the European Commission, 2014), with the addition of } \\
\text { the essential basic requirements described in Annex ZA of the same harmonised } \\
\text { standard (Pavan et al. 2019). It will then be possible to generate the DoP of the product }\end{array}$ \\
\hline 4 & $\begin{array}{l}\text { The point shows the fields of the technical data sheet as defined in the UNI/TS } \\
\text { 11337-3:2015 standard. The only exception is the section on sustainability, more } \\
\text { specifically described through the insertion of all environmental sustainability indicators } \\
\text { in accordance with the UNI EN 15804:2014 standard, in order to grant the end user the } \\
\text { ability to quantify the ecological impact at every stage the product life cycle ('from } \\
\text { cradle to grave') }\end{array}$ \\
\hline 5 & $\begin{array}{l}\text { Not selectable for all types of products, it contains the guide dossier, a document that } \\
\text { aims to contain all the information concerning the transport, handling and storage, } \\
\text { works/installation, use and maintenance, disposal and prevention and security. }\end{array}$ \\
\hline 6 & $\begin{array}{l}\text { In this section, there is the option to insert } 2 \mathrm{D} \text { and } 3 \mathrm{D} \text { models in both the proprietary and } \\
\text { the open-source formats by indicating the LOD (Level Of Development) }\end{array}$ \\
\hline 7 & $\begin{array}{l}\text { Document management aims at ensuring that the manufacturer/dealer attaches any } \\
\text { additional certifications and attestations, providing a further opportunity to transparently } \\
\text { leverage its product. Doc, pdf, docx, xls, xlsx, png and jpg files types can be inserted }\end{array}$ \\
\hline 8 & $\begin{array}{l}\text { In this step, the partner portals with which technological interchange interfaces have } \\
\text { been developed are proposed; it will, therefore, be possible to move the product to } \\
\text { portals such as the ones belonging to TraceParts, project partners boasting } 15 \text { million } \\
\text { users, thus exponentially increasing visibility on the market }\end{array}$ \\
\hline 9 & $\begin{array}{l}\text { This section aims to sensitise the compiler, showing the percentages of completeness } \\
\text { achieved in the previous points }\end{array}$ \\
\hline 10 & $\begin{array}{l}\text { The last point allows to create a version of the technical data sheet and guide dossier, if } \\
\text { any, anonymous. This activity wants to meet the requirements under public contracts, } \\
\text { i.e. providing these documents free from any information that would allow the specific } \\
\text { product or manufacturer to be traced }\end{array}$ \\
\hline
\end{tabular}


Fig. 2 Graphical distribution of the product classification

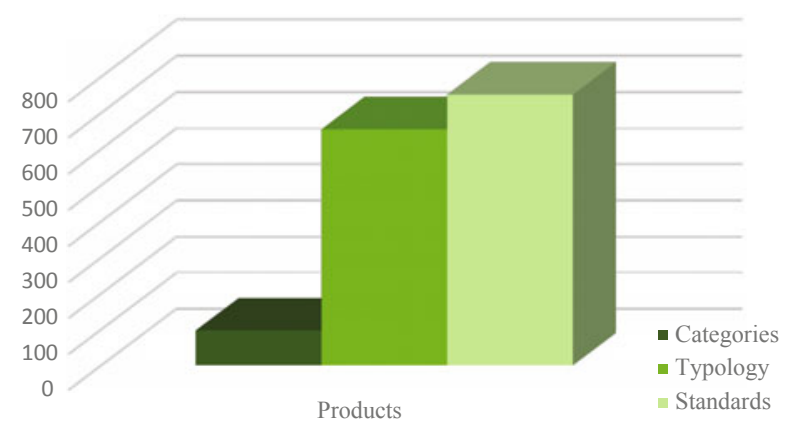

Fig. 3 Example of a masonry brick element using the portal's IFC viewer

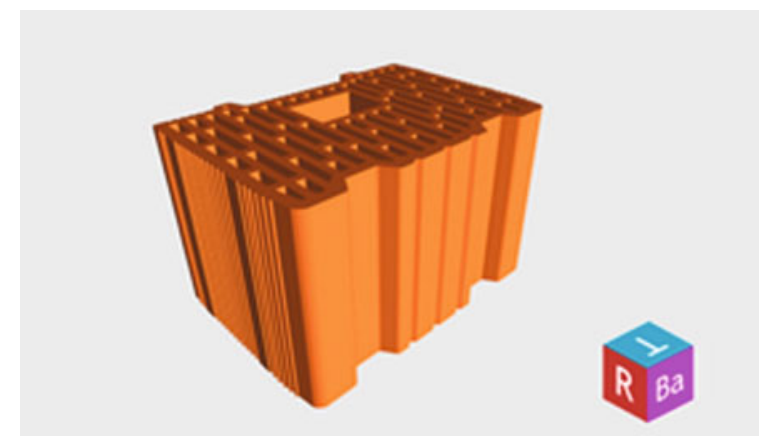

\section{Concluding Remarks}

The impacts of the use of this portal are numerous and improve the whole chain of the construction industry. The platform is positioned as the top product portal for the construction industry, meeting the specifications of the new UNI/TS 11337-3:2015 standard that lays down the criteria for coding construction works and products, activities and resources. Thanks to BIMReL, component manufacturers for the construction industry have the opportunity to publish their catalogues not only on the Italian market but also internationally. In addition, the simple and immediate access to the BIMReL platform for citizens allows the possibility to easily check and compare each characteristics and performance of materials and products, creating concrete awareness of their environmental impacts. In conclusion, the interoperable platform for the management of the BIM library in the Lombardy Region will, therefore, not be a simple 'objects container' but, thanks to the information breakdown, adherence to the new standards and the systematisation of the latest ICT tools system, it will improve the entire supply chain in the construction industry, providing citizens with a smart channel of data access and use. 


\section{References}

Duddy K, Beazley S, Drogemuller R, Kiegeland J (2013) A platform—independent product library for BIM. In: Ma Z, Zhang J, et al Proceedings of the 30th CIB W78 international conference (Beijing, China) WQBook

Gudnason G, Pauwels P (2016) SemCat: Publishing and Accessing Building Product Information as Linked Data. In: Proceedings of 11th European Conference on product \& process modelling (ECPPM), pp 659-666

ISO-International Organization for Standardization (2017) ISO 21930:2017 Sustainability in buildings and civil engineering works-Core rules for environmental product declarations of construction products and services

Kim JB, Jeong W, Clayton MJ, Haberl JS, Yan W (2015) Developing a physical BIM library for Building thermal energy simulation. Automat Construct 50:16-28

Lucky MN, Pasini D, Lupica Spagnolo S (2019) Product data management for sustainability: an interoperable approach for sharing product data in a BIM environment. In: IOP conference series, Earth Environ Sci 296012053

Lupica Spagnolo S, Pasini D, Daniotti B, Pavan A, Mazza N, Valra A (2017) A BIM-based platform for managing the whole building life cycle. In: Ciribini A, Alaimo G, et al (eds) Proceedings of ISTeA 2017 conference (Florence, Italy) Re-shaping the construction industry, pp. 112-121

Pavan A, Mirarchi C, Amosso G, Lucky MN, Pasini D, Daniotti B, Lupica Spagnolo S (2019) BIMReL: a new BIM object library using Construction Product Regulation attributes (CPR 350/11; ZA annex) IOP Conference Series, Earth Environ Sci 296012052

Pasini D, Caffi V, Daniotti B, Lupica Spagnolo S (2017) The innovance BIM library approach. Innovat Infrastruct Solut 2(1):p15

Signorini M, Frigeni S, Lupica Spagnolo S (2019) Integrating environmental sustainability indicators in BIM-based product datasheets. IOP Conference series, Earth Environ Sci 296012028

The European Parliament and the Council (2011) Regulation (EU) No. 305/2011 of 9 March 2011 laying down harmonised conditions for the marketing of construction products and repealing Council Directive 89/106/EEC

The European Commission (2014) Commission Delegated Regulation (EU) No 574/2014 amending Annex III to Regulation (EU) No 305/2011 of the European Parliament and of the Council on the model to be used for drawing up a declaration of performance on construction products

UNI-Ente Italiano di Normazione (2014) UNI EN 15804:2014 Sustainability of construction works-Environmental product declarations - Core rules for the product category of construction products

UNI—Ente Italiano di Normazione (2015) UNI/TS 11337-3:2015 Building and civil engineering works-Codification criteria for construction products and works, activities and resources-Part 3: Models of collecting, organizing and recording the technical information for construction products 
Open Access This chapter is licensed under the terms of the Creative Commons Attribution 4.0 International License (http://creativecommons.org/licenses/by/4.0/), which permits use, sharing, adaptation, distribution and reproduction in any medium or format, as long as you give appropriate credit to the original author(s) and the source, provide a link to the Creative Commons license and indicate if changes were made.

The images or other third party material in this chapter are included in the chapter's Creative Commons license, unless indicated otherwise in a credit line to the material. If material is not included in the chapter's Creative Commons license and your intended use is not permitted by statutory regulation or exceeds the permitted use, you will need to obtain permission directly from the copyright holder.

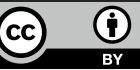

